\title{
Fluorescence and Opalescence of Two Dental Composite Resins
}

\author{
Masoomeh Hasani Tabatabaei ${ }^{1} \quad$ Alireza Mahmoudi Nahavandi ${ }^{2}$ Sotude Khorshidi ${ }^{3}$ \\ Sedighe Sadat Hashemikamangar ${ }^{1}$
}

${ }^{1}$ Department of Operative Dentistry, Dental School, Tehran University of Medical Sciences, Tehran, Iran

${ }^{2}$ Color Imaging and Color Image Processing Department, Institute

for Color Science and Technology (ICST), Tehran, Iran

${ }^{3}$ Department of Operative Dentistry, Tehran University of Medical

Science, Tehran, Iran

\begin{abstract}
Address for correspondence Sedighe Sadat Hashemikamangar, DDS MS, Operative Department, Dental School, International Campus,

Tehran University of Medical Sciences, Kargar St, Tehran, 1911837413 Iran (e-mail: smhk58950@gmail.com).
\end{abstract}

Eur J Dent 2019;13:527-534

\begin{abstract}
Keywords

- composite resins

- fluorescence

- opalescence

- spectrophotometry

Objective Lifelike esthetic appearance of dental restorations is among the main goals in restorative dentistry. This study aimed to assess and compare the opalescence and fluorescence of two dental composite resins.

Materials and Methods This in vitro experimental study evaluated the A2 shade of Filtek Z350 XT Enamel, Filtek Z350 XT Dentin, Aelite Aesthetic Enamel, and Aelite All Purpose Body composite resins. Composite discs were fabricated with $10 \mathrm{~mm}$ diameter and 0.5 and $1 \mathrm{~mm}$ thicknesses $(n=2)$ using a plexiglass mold and subjected to colorimetry. The color parameters were determined according to the International Commission on Illumination (CIE) $\mathrm{L}^{*} \mathrm{a}^{*} \mathrm{~b}^{*}$ system using a spectrophotometer. The fluorescence and opalescence were also measured and reported separately for 0.5 and $1 \mathrm{~mm}$ thicknesses of Z350, Aelite Body, and Enamel composite resins. To determine the opalescence, the color of samples in the reflectance mode was measured using a calibration cylinder and in the transmittance mode in presence of $100 \%$ ultraviolet (UV) light. To determine the fluorescence, the color of samples against a white background in the reflectance mode in presence or absence of $100 \%$ UV light was measured.

Statistical Analysis Data were analyzed using SPSS via three-way analysis of variance and independent $t$-test.

Results The fluorescence of $0.5 \mathrm{~mm}$ thickness of all composites was higher than that of $1 \mathrm{~mm}$ thickness $(p<0.05)$. The fluorescence of Aelite was higher than that of Z350 ( $p<0.05)$. The fluorescence of Aelite Enamel was higher than that of Aelite Body irrespective of their thickness, but the results were opposite for Z350 $(p<0.05)$. In Aelite composite, opalescence increased by an increase in thickness $(p<0.05)$. The opalescence of Aelite was significantly higher than that of Z350 $(p<0.05)$. The opalescence of $0.5 \mathrm{~mm}$ thickness of Aelite Enamel was higher than that of Aelite Body, while the opalescence of $1 \mathrm{~mm}$ thickness of Z350 Body was higher than that of Z350 Enamel $(p<0.05)$.

Conclusion Thickness, type, and brand of composite resins affected their fluorescence and opalescence.
\end{abstract}

\section{Introduction}

The opalescence and fluorescence of restorative materials along with their conventional color parameters such as value, hue, and chroma play an important role in optical properties of an ideal restoration for natural teeth. ${ }^{1,2}$

In the process of production of restorative materials to ideally mimic the optical properties of natural teeth, it is 
imperative to find a scientific path to quantitatively assess the optical properties of teeth. The Enamel of natural teeth has opalescence. Light scattering in shorter wavelengths of the visible spectrum creates a blue tint in the reflected color and an orange/brown tint in the transmitted color. ${ }^{3}$ Light emission in the visible light spectrum is due to the presence of small particles. The opalescence of dental materials is defined as the difference in chroma between the reflected and transmitted colors. ${ }^{4-6}$ Human teeth show unique opalescence, translucency, and fluorescence, which should be restored by esthetic restorative materials. Esthetic dental restorations should have optical properties similar to those of natural teeth in terms of opalescence.

Natural teeth have a blue fluorescence under ultraviolet (UV) light; thus, they appear whiter and lighter under daylight. ${ }^{7,8}$ The fluorescence is defined as the emission of light by natural teeth that have absorbed light. Irradiation of dentin by $365 \mathrm{~nm}$ light causes a fluorescence emission at $440 \pm 10 \mathrm{~nm}$ peak. ${ }^{9}$ Fluorescence of dental materials can be determined by the color difference in presence and absence of UV light using a spectrophotometer. ${ }^{10,11}$

The opalescence of resin materials is determined by the difference in the refractive index of resin matrix and fillers. ${ }^{5}$ On the other hand, the fluorescence of resin materials is determined by the presence of certain fluorescent pigments in their structure rather than their resin matrix or filler particles. During the process of polymerization, the refractive index of resin matrix increases, but the refractive index of fillers remains unchanged. Therefore, difference in the refractive index of resin matrix and inorganic fillers and the difference in opalescence and fluorescence of resin restorative materials are affected by the polymerization process.

Lee systematically reviewed the opalescence of human teeth and esthetic restorative materials and suggested that materials with the ability to mimic the opalescent properties of the Enamel should be further evaluated. ${ }^{12}$ Thus, further investigations are required about the opalescence and fluorescence of composite resins. The light transmission by composite resins has been the topic of many previous studies. However, the translucency, opalescence, and light transmission of composite resins when applied in different thicknesses have not been well investigated. ${ }^{13}$

Composite resins have different color shades, resin matrix composition, and fillers. The opalescence and fluorescence of composite resins may vary depending on their type and color shade. The purpose of this study was to assess the opalescence and fluorescence of two composite resins. The effect of composite thickness, the Enamel and Body types of composite resins, and their brand on opalescence and fluorescence was also studied. The null hypothesis of this study was that the opalescence and fluorescence of the two tested composite resins would not be significantly different, and composite thickness, the Enamel and Body types of composite resins, and their brand would have no significant effect on opalescence and fluorescence of the tested composite resins.

\section{Materials and Methods}

This in vitro experimental study evaluated the opalescence and fluorescence of A2 shade of Filtek Z350 XT Enamel, Filtek Z350 XT Dentin, Aelite Aesthetic Enamel, and Aelite All Purpose Body composite resins. - Table 1 presents the characteristics of these composite resins.

Composite discs with 0.5 and $1 \mathrm{~mm}$ thicknesses and $10 \mathrm{~mm}$ diameter were fabricated of the above-mentioned composites using a plexiglass mold ( $n=2$ of each thickness of each composite). The mold was placed over a glass slab and composite resin was applied and packed into the mold. A slide was placed over it and compressed. Light curing was performed for 60 seconds using a light curing unit(TPC,Valo,Ultradent,United States)with a light intensity of $1,000 \mathrm{~mW} / \mathrm{cm}^{2}$. The output light energy was checked by a radiometer. The samples were removed from the molds after polymerization.

Table 1 Characteristics of the composite resins used in this study

\begin{tabular}{|l|l|l|l|l|}
\hline Composite name & Shade & Composite type & Composition & Manufacturer \\
\hline Filtek Z350 XT & A2 & Nano-fill & $\begin{array}{l}\text { UDMA } \\
\text { Bis-GMA } \\
\text { Bis-EMA } \\
\text { PEGDMA } \\
\text { TEGDMA } \\
\text { Silica } \\
\text { Zirconia }\end{array}$ & $\begin{array}{l}\text { 3M ESPE, } \\
\text { St. Paul, Minnesota, United States }\end{array}$ \\
\hline Aelite All Purpose Body & A2 & Microhybrid & $\begin{array}{l}\text { Bis-EMA } \\
\text { TEGDMA } \\
\text { Glass filler } \\
\text { Amorphous Silica }\end{array}$ & BISCO Schaumburg, Illinois, United States \\
\hline AELITE Aesthetic Enamel & A2 & Reinforced nano-fill & $\begin{array}{l}\text { Bis-GMA } \\
\text { Bis-EMA } \\
\text { Glass frit } \\
\text { Amorphous Silica }\end{array}$ & BISCO Schaumburg, Illinois, United States \\
\hline
\end{tabular}

Abbreviations: Bis-EMA, bisphenol A-polyethylene glycol diether dimethacrylate; Bis-GMA, bisphenol A-glycerolate dimethacrylate; PEGDMA, polyethylene glycol dimethacrylate; TEGDMA, tetraethylene glycol dimethacrylate; UDMA, urethane dimethacrylate. 
The samples then underwent colorimetry, and color parameters were measured by a spectrophotometer (CS-2000; Konika Minolta) according to the CIE L*a*b* system. The opalescence and fluorescence were also determined according to the CIE $\mathrm{L}^{*} \mathrm{a}^{*} \mathrm{~b}^{*}$ system. To determine the opalescence, the color of samples in the reflectance mode was measured using a calibration cylinder and in the transmittance mode in the presence of $100 \%$ UV light. To determine the fluorescence, the color of samples against a white background in the reflectance mode in presence or absence of $100 \%$ UV light was measured. The measurements were repeated twice and the mean value was calculated and used for statistical analysis. The opalescence was calculated using the formula below where $\mathrm{T}$ and $\mathrm{R}$ show transmittance and reflectance, respectively ${ }^{4-6}$ :

$$
\mathrm{OP}=\left(\left(\mathrm{CIE} a_{100}^{*}-\mathrm{CIE} a_{0}^{*}\right)^{2}+\left(\mathrm{CIE} b_{100}^{*}-\mathrm{CIE} b_{0}^{*}\right)^{2}\right)^{0.5}
$$

Fluorescence, which is defined as color difference $\left(\Delta E^{*} a b\right)$ in presence and absence of UV light, was calculated using the formula below:

$$
\mathrm{FL}=\left(\left(\mathrm{CIEL}_{100}^{*}-\mathrm{CIEL}_{0}^{*}\right)^{2}+\left(\mathrm{CIE} a_{100}^{*}-\mathrm{CIE} a_{0}^{*}\right)^{2}+\left(\mathrm{CIE} b_{100}^{*}-\mathrm{CIE} b_{0}^{*}\right)^{2}\right)^{0.5}
$$

The 0 and 100 values in this formula indicate presence of $100 \%$ UV light and absence of UV light in a standard CIE device, respectively. ${ }^{14}$

A spectroradiometer (CS-2000; Konika Minolta) was used to measure the reflectance and transmittance of the samples. To measure transmittance, an incandescent light source was used by a constant power supply. In front of the power supply, a paper was folded such that an ideal emission of light was obtained. Next, a black plexiglass holder fabricated by a laser cutting machine was used to hold the samples. - Fig. 1 illustrates the measurement of transmittance by a spectroradiometer. The transmittance was read with the angle of device adjusted at $0.2^{\circ}$.
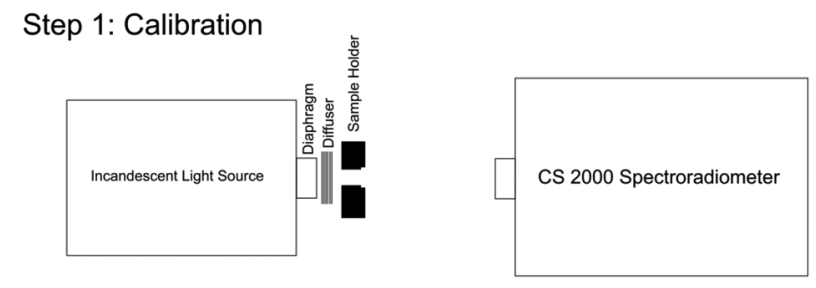

Step 2: Measurement
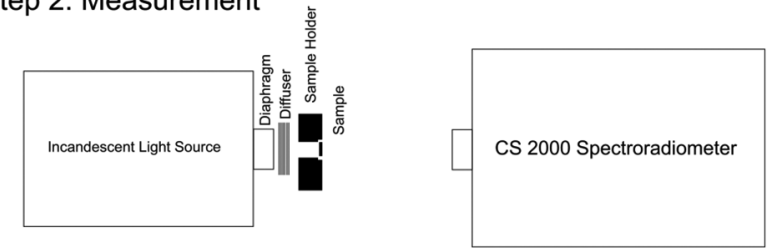

Fig. 1 Measurement of transmittance by a spectroradiometer.
Considering $80 \mathrm{~cm}$ distance of the sample from the spectroradiometer, a circle with $2.8 \mathrm{~mm}$ diameter at the center of the sample was measured.

For measurement of reflectance, two incandescent light sources illuminated the sample with $45^{\circ}$ angle. The lamps were lit by a power source and the device was calibrated using a white tile. Next, the sample was placed in the holder. Since the samples were semitransparent, an optical trap was placed behind the sample to prevent the reflection of light that passed through the sample and hit the trap. The reflectance of the sample was then read. -Fig. 2 illustrates the measurement of reflectance by a spectroradiometer.

Samples of Aelite and Z350 composites in Enamel and Body types were fabricated with 0.5 and $1 \mathrm{~mm}$ thickness and their reflectance and transmittance were measured by the spectroradiometer. Accordingly, their color parameters according to the CIE $\mathrm{L}^{*} \mathrm{a}^{*} \mathrm{~b}^{*}$ system were calculated using CS-10W software under D65 $/ 2^{\circ}$.

$$
\mathrm{op}=\left(\left(\Delta a^{*}\right)^{2}+\left(\Delta b^{*}\right)^{2}\right)^{0.5}
$$

The opalescence of the samples was calculated using the difference in chromaticity of the samples in transmittance and reflectance modes.

To measure the fluorescence, maximum excitation wavelength was first determined using a fluorescence spectrometer (LS55; PerkinElmer). Maximum scattering efficiency of both Aelite and Z350 was noted at $390 \mathrm{~nm}$ wavelength. Thus, LED lamps with $385 \mathrm{~nm}$ wavelength of radiation were obtained. Seven $1 \mathrm{~W}$ LED lamps were mounted on a board, connected in series, and lit using a $21 \mathrm{~V}, 7 \mathrm{~W}$ driver. The light intensity was adjusted by a potentiometer such that the maximum reflectance of the samples did not exceed 300\% (which was the maximum measurement power of device). Fluorescence was measured in two modes. First, incandescent lamps with zero UV content were used and the reflectance of the samples was measured under this light. Second, LED lamps were added to the incandescent lamps, calibration was performed using a white tile, and reflectance was measured again.
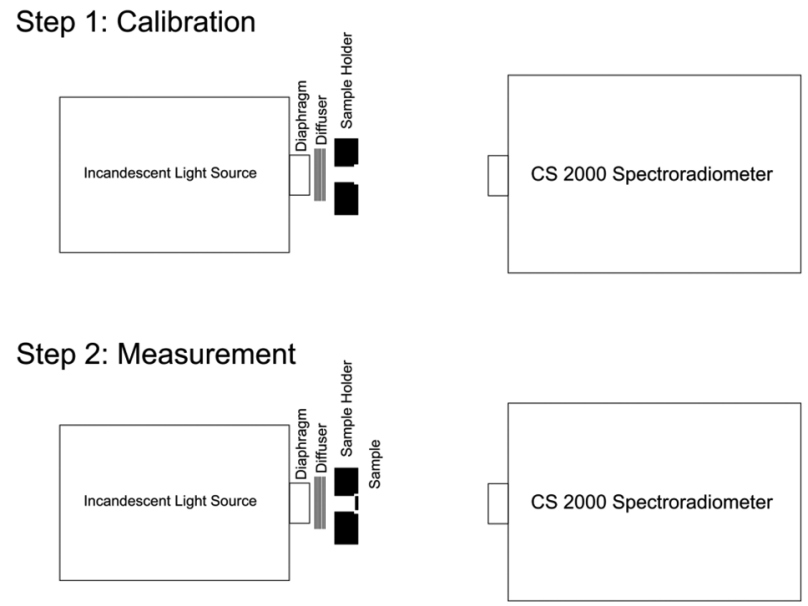

Fig. 2 Measurement of reflectance by a spectroradiometer. 

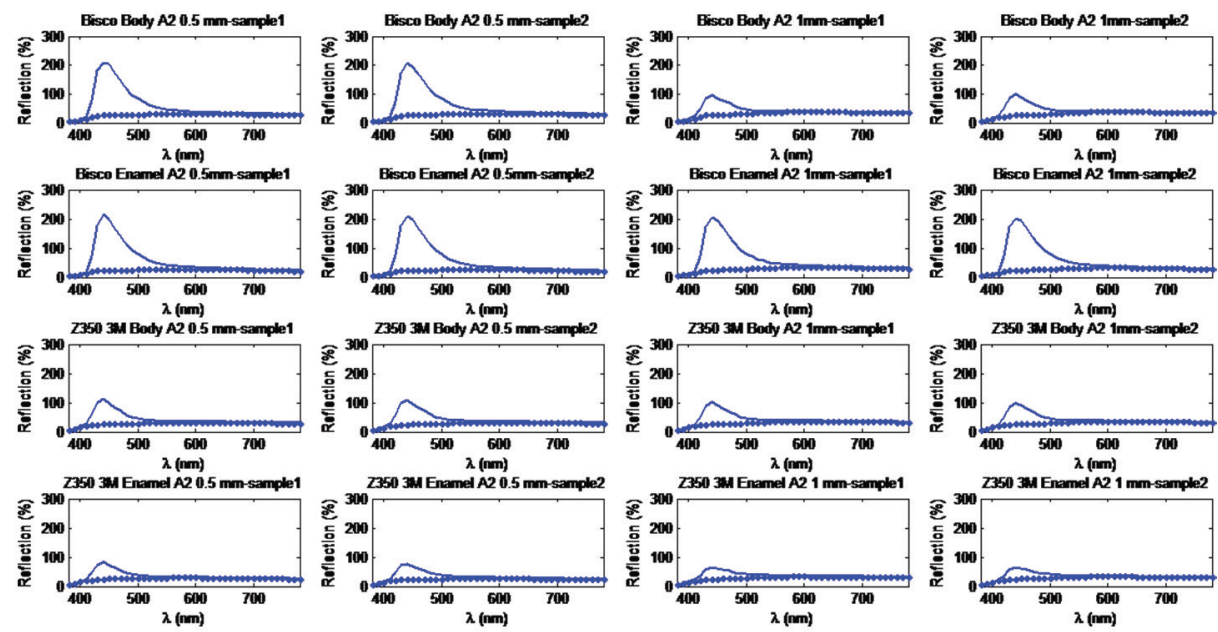

Fig. 3 Reflectance spectra of the samples. Continuous spectra indicate the total radiation factor, while the dotted spectra indicate reflectance.

Table 2 Effect of thickness of composite samples on their fluorescence $(n=2)$

\begin{tabular}{|c|c|c|c|c|c|}
\hline \multicolumn{3}{|c|}{ Thickness } & Mean & SD & SE mean \\
\hline \multirow[t]{4}{*}{$0.5 \mathrm{~mm}$} & \multirow[t]{2}{*}{ AELITE } & Body & 179.8800 & 0.77782 & 0.55000 \\
\hline & & Enamel & 188.7500 & 4.69519 & 3.32000 \\
\hline & \multirow[t]{2}{*}{ Z350 } & Body & 86.1150 & 0.68589 & 0.48500 \\
\hline & & Enamel & 55.1000 & 2.40416 & 1.70000 \\
\hline \multirow[t]{4}{*}{$1 \mathrm{~mm}$} & \multirow[t]{2}{*}{ AELITE } & Body & 69.1150 & 3.98101 & 2.81500 \\
\hline & & Enamel & 178.8000 & 3.86080 & 2.73000 \\
\hline & \multirow[t]{2}{*}{ Z350 } & Body & 74.4000 & 2.16375 & 1.53000 \\
\hline & & Enamel & 39.9500 & 0.39598 & 0.28000 \\
\hline
\end{tabular}

Abbreviations: SD, standard deviation; SE, standard error.

The fluorescence of 16 samples was measured. The results are presented in -Fig. 3. As shown, the obtained spectra completely matched the expected spectrum for a fluorescent sample. Principal component analysis revealed that $99.5 \%$ of the cumulative variance of the peaks was within one vector. In other words, the fluorescence output of the samples was the same. Thus, for the purpose of comparison of fluorescence of the samples, the difference in fluorescence output at the peak relative to the reflectance was determined.

Data were analyzed using SPSS version 25 (SPSS Inc., Chicago, Illinois, United States) via one-way analysis of variance (ANOVA), two-way ANOVA, three-way ANOVA, and independent $t$-test at $p<0.05$ level of significance.

\section{Results}

\section{Fluorescence}

According to three-way ANOVA, the interaction effect of the type of composite, thickness of composite, and brand of composite on fluorescence was significant $(p=0.00)$.

- Table 2 presents the effect of thickness of composite samples on their fluorescence. In All Purpose Body Aelite, the difference in fluorescence of 0.5 and $1 \mathrm{~mm}$ thickness was significant $(p=0.001)$ and the fluorescence of $0.5 \mathrm{~mm}$ thickness was higher. The difference in fluorescence of 0.5 and $1 \mathrm{~mm}$ thickness of Aelite Aesthetic Enamel was not significant $(p=0.147)$. The difference in fluorescence of 0.5 and $1 \mathrm{~mm}$ thickness of Filtek Z350 XT Body was significant and 0.5 thickness of this composite showed higher fluorescence $(p=0.018)$. The difference in fluorescence of 0.5 and $1 \mathrm{~mm}$ thickness of Filtek Z350 XT Enamel was also significant and 0.5 thickness of this composite showed higher fluorescence $(p=0.013)$.

- Table 3 presents the mean fluorescence of different thicknesses of composites. The results showed that $0.5 \mathrm{~mm}$ thickness of Aelite Body had higher fluorescence than $0.5 \mathrm{~mm}$ thickness of Z350 Body ( $p=0.000$ ). However, the difference in this respect between $1 \mathrm{~mm}$ thickness of Aelite Body and Z350 Body was not significant ( $p=0.241)$. The difference in $0.5 \mathrm{~mm}$ thickness of Aelite Enamel and Z350 Enamel was also significant and Aelite showed higher fluorescence $(p=0.001)$. Also, $1 \mathrm{~mm}$ thickness of Aelite Enamel had significantly higher fluorescence than Z350 Enamel ( $p=0.000$ ).

- Table 4 presents the effect of type of composite on fluorescence of 0.5 and $1 \mathrm{~mm}$ thicknesses of the two composites. The difference in fluorescence of $0.5 \mathrm{~mm}$ thickness of Aelite Body and Enamel was not significant ( $p=0.119$ ). However, the fluorescence of $0.5 \mathrm{~mm}$ thickness of Z350 
Table 3 Mean and SE of fluorescence of different thicknesses of composites based on the composite brand

\begin{tabular}{|c|c|c|c|c|c|}
\hline \multicolumn{3}{|c|}{ Composite } & \multirow{2}{*}{$\begin{array}{l}\text { Mean } \\
179.8800 \\
\end{array}$} & \multirow{2}{*}{$\begin{array}{l}\text { SD } \\
0.77782\end{array}$} & \multirow{2}{*}{$\begin{array}{l}\text { SE mean } \\
0.55000\end{array}$} \\
\hline AELITE & Body & $0.5 \mathrm{~mm}$ & & & \\
\hline & & $1 \mathrm{~mm}$ & 69.1150 & 3.98101 & 2.81500 \\
\hline & Enamel & $0.5 \mathrm{~mm}$ & 188.7500 & 4.69519 & 3.32000 \\
\hline & & $1 \mathrm{~mm}$ & 178.8000 & 3.86080 & 2.73000 \\
\hline \multirow[t]{4}{*}{ Z350 } & \multirow[t]{2}{*}{ Body } & $0.5 \mathrm{~mm}$ & 86.1150 & 0.68589 & 0.48500 \\
\hline & & $1 \mathrm{~mm}$ & 74.4000 & 2.16375 & 1.53000 \\
\hline & \multirow[t]{2}{*}{ Enamel } & $0.5 \mathrm{~mm}$ & 55.1000 & 2.40416 & 1.70000 \\
\hline & & $1 \mathrm{~mm}$ & 39.9500 & 0.39598 & 0.28000 \\
\hline
\end{tabular}

Abbreviations: SD, standard deviation; SE, standard error.

Table 4 Effect of type of composite on fluorescence of 0.5 and $1 \mathrm{~mm}$ thicknesses of the two composites

\begin{tabular}{|c|c|c|c|c|c|}
\hline \multicolumn{3}{|l|}{ Type } & Mean & SD & SE mean \\
\hline \multirow[t]{4}{*}{ Body } & \multirow[t]{2}{*}{$0.5 \mathrm{~mm}$} & AELITE & 179.8800 & 0.77782 & 0.55000 \\
\hline & & Z350 & 86.1150 & 0.68589 & 0.48500 \\
\hline & \multirow[t]{2}{*}{$1 \mathrm{~mm}$} & AELITE & 69.1150 & 3.98101 & 2.81500 \\
\hline & & Z350 & 74.4000 & 2.16375 & 1.53000 \\
\hline \multirow[t]{4}{*}{ Enamel } & \multirow[t]{2}{*}{$0.5 \mathrm{~mm}$} & AELITE & 188.7500 & 4.69519 & 3.32000 \\
\hline & & Z350 & 55.1000 & 2.40416 & 1.70000 \\
\hline & \multirow[t]{2}{*}{$1 \mathrm{~mm}$} & AELITE & 178.8000 & 3.86080 & 2.73000 \\
\hline & & $Z 350$ & 39.9500 & 0.39598 & 0.28000 \\
\hline
\end{tabular}

Abbreviations: SD, standard deviation; SE, standard error.

Table 5 Effect of thickness of composite resins on their opalescence $(n=2)$

\begin{tabular}{|c|c|c|c|c|c|}
\hline \multicolumn{3}{|c|}{ Thickness } & \multirow{2}{*}{$\begin{array}{l}\text { Mean } \\
17.4100\end{array}$} & \multirow{2}{*}{$\begin{array}{l}\text { SD } \\
0.01414\end{array}$} & \multirow{2}{*}{$\begin{array}{l}\text { SE mean } \\
0.01000\end{array}$} \\
\hline $0.5 \mathrm{~mm}$ & Body & AELITE & & & \\
\hline & & Z350 & 6.1250 & 0.12021 & 0.08500 \\
\hline & Enamel & AELITE & 18.8000 & 0.02828 & 0.02000 \\
\hline & & Z350 & 6.4700 & 0.38184 & 0.27000 \\
\hline \multirow[t]{4}{*}{$1 \mathrm{~mm}$} & \multirow[t]{2}{*}{ Body } & AELITE & 21.9300 & 0.73539 & 0.52000 \\
\hline & & Z350 & 6.7850 & 0.27577 & 0.19500 \\
\hline & \multirow[t]{2}{*}{ Enamel } & AELITE & 19.4000 & 0.08485 & 0.06000 \\
\hline & & Z350 & 5.3950 & 0.13435 & 0.09500 \\
\hline
\end{tabular}

Abbreviations: SD, standard deviation; SE, standard error.

Body was higher than that of Z350 Enamel ( $p=0.003)$. The fluorescence of $1 \mathrm{~mm}$ thickness of Aelite Enamel was higher than that of Aelite Dentin $(p=0.001)$. The fluorescence of $1 \mathrm{~mm}$ thickness of Z350 Body was higher than that of Z350 Enamel $(p=0.002)$.

\section{Opalescence}

According to three-way ANOVA, the interaction effect of the type of composite, thickness of composite, and brand of composite on opalescence was significant $(p=0.00)$.

- Table 5 shows the effect of thickness of composite resins on their opalescence. The opalescence of $1 \mathrm{~mm}$ thickness of Aelite All Purpose Body was significantly higher than that of $0.5 \mathrm{~mm}$ thickness $(p=0.013)$. The opalescence of $1 \mathrm{~mm}$ thickness of Aelite Esthetic Enamel was significantly higher than that of $0.5 \mathrm{~mm}$ thickness ( $p=0.011)$. This difference was not significant between 0.5 and $1 \mathrm{~mm}$ thicknesses of Z350 XT Body ( $p=0.09$ ) or Z350 XT Enamel $(p=0.06)$.

- Table 6 shows the effect of composite brand on opalescence. The opalescence of $0.5 \mathrm{~mm}$ thickness of Aelite Body was higher than that of Z350 Body $(p=0.000)$. The opalescence of $1 \mathrm{~mm}$ thickness of Aelite Body was higher than that of Z350 Body ( $p=0.001)$. The opalescence of $0.5 \mathrm{~mm}$ thickness of Aelite Enamel was higher than that of Z350 Enamel $(p=0.000)$. The opalescence of $1 \mathrm{~mm}$ thickness of Aelite Enamel was also higher than that of Z350 Enamel $(p=0.000)$.

- Table 7 shows the effect of type of composite on opalescence. The opalescence of $0.5 \mathrm{~mm}$ thickness of Aelite Enamel was higher than that of Aelite Body $(p=0.000)$. The 
Table 6 Effect of composite brand on opalescence $(n=2)$

\begin{tabular}{|c|c|c|c|c|c|}
\hline \multicolumn{3}{|c|}{ Composite } & Mean & SD & SE mean \\
\hline \multirow[t]{4}{*}{ AELITE } & \multirow[t]{2}{*}{$0.5 \mathrm{~mm}$} & Body & 17.4100 & 0.01414 & 0.01000 \\
\hline & & Enamel & 18.8000 & 0.02828 & 0.02000 \\
\hline & \multirow[t]{2}{*}{$1 \mathrm{~mm}$} & Body & 21.9300 & 0.73539 & 0.52000 \\
\hline & & Enamel & 19.4000 & 0.08485 & 0.06000 \\
\hline \multirow[t]{4}{*}{ Z350 } & \multirow[t]{2}{*}{$0.5 \mathrm{~mm}$} & Body & 6.1250 & 0.12021 & 0.08500 \\
\hline & & Enamel & 6.4700 & 0.38184 & 0.27000 \\
\hline & \multirow[t]{2}{*}{$1 \mathrm{~mm}$} & Body & 6.7850 & 0.27577 & 0.19500 \\
\hline & & Enamel & 5.3950 & 0.13435 & 0.09500 \\
\hline
\end{tabular}

Abbreviations: SD, standard deviation; SE, standard error.

Table 7 Effect of type of composite on opalescence $(n=2)$

\begin{tabular}{|c|c|c|c|c|c|}
\hline \multicolumn{3}{|l|}{ Type } & Mean & SD & SE mean \\
\hline \multirow[t]{4}{*}{ Body } & \multirow[t]{2}{*}{ AELITE } & $0.5 \mathrm{~mm}$ & 17.4100 & 0.01414 & 0.01000 \\
\hline & & $1 \mathrm{~mm}$ & 21.9300 & 0.73539 & 0.52000 \\
\hline & \multirow[t]{2}{*}{ Z350 } & $0.5 \mathrm{~mm}$ & 6.1250 & 0.12021 & 0.08500 \\
\hline & & $1 \mathrm{~mm}$ & 6.7850 & 0.27577 & 0.19500 \\
\hline \multirow[t]{4}{*}{ Enamel } & \multirow[t]{2}{*}{ AELITE } & $0.5 \mathrm{~mm}$ & 18.8000 & 0.02828 & 0.02000 \\
\hline & & $1 \mathrm{~mm}$ & 19.4000 & 0.08485 & 0.06000 \\
\hline & \multirow[t]{2}{*}{ Z350 } & $0.5 \mathrm{~mm}$ & 6.4700 & 0.38184 & 0.27000 \\
\hline & & $1 \mathrm{~mm}$ & 5.3950 & 0.13435 & 0.09500 \\
\hline
\end{tabular}

Abbreviations: SD, standard deviation; SE, standard error.

opalescence of $0.5 \mathrm{~mm}$ thickness of Z350 Enamel and Body was not significantly different ( $p=0.347$ ). The difference in opalescence of $1 \mathrm{~mm}$ thickness of Aelite Body and Enamel was not significant either $(p=0.125)$. The difference in opalescence of $1 \mathrm{~mm}$ thickness of Z350 Body and Enamel was significant and Z350 Body showed higher opalescence $(p=0.023)$.

\section{Discussion}

Color parameters such as opalescence of dental composites depend on many factors such as their resin matrix composition, amount and composition of fillers, pigments, and other additives. ${ }^{15-18}$ This study assessed and compared the opalescence and fluorescence of two bisphenol A-glycerolate dimethacrylate-based dental composites. Z350 is a nano-filled composite containing silica nano-fillers measuring $20 \mathrm{~nm}$ in size, zirconia/silica nanoclusters measuring 0.4 to $0.6 \mu \mathrm{m}$ in size and 78.5 wt\% filler volume. ${ }^{19,20}$ Aelite All Purpose Body is a methacrylate-based microhybrid composite with glass-filled amorphous silica fillers measuring 0.4 to $0.7 \mu \mathrm{m}$ in size and $73 \mathrm{wt} \%$ filler volume. Aelite Aesthetic Enamel is a reinforced nano-fill composite with a mean particle size of $0.04 \mu \mathrm{m} .{ }^{21-23}$ The results showed higher fluorescence of Aelite brand in all groups (except for $1 \mathrm{~mm}$ thickness of Aelite Body which had no significant difference). Comparison of the effect of type of composite on fluorescence revealed greater fluorescence of $0.5 \mathrm{~mm}$ thickness of Z350 Body compared to Enamel, while the difference between $0.5 \mathrm{~mm}$ thickness of Aelite Body and Enamel was not significant. The fluorescence of $1 \mathrm{~mm}$ thickness of Z350 Body was higher than that of Enamel, while the fluorescence of $1 \mathrm{~mm}$ thickness of Aelite Enamel was higher than that of Aelite Body.

Lee $^{16}$ evaluated the effect of size and amount of fillers on transmitted and reflected colors of composites in $1 \mathrm{~mm}$ thickness and found no significant association. In our study, the fluorescence of $0.5 \mathrm{~mm}$ thickness of composites was higher in all groups (except for Aelite Aesthetic Enamel which showed no significant difference). No previous study was found in this respect to compare our results with.

Meller and Klein ${ }^{24}$ evaluated the fluorescence of 234 composite samples of different brands in Enamel and Body types. They concluded that the fluorescence of different shades of the same brand is variable. They reported descriptive results and showed different maximum intensity of fluorescence, which indicates absence of standard fluorescent properties among different shades even from the same brand. The same was true regarding Enamel and Body composites. In some brands, the maximum intensity of fluorescence was higher in Enamel composite type. Also, shades applied on the surface or subsurface layer in multi-layering technique showed more intense fluorescence, which is in contrast to natural teeth in which dentin has a greater fluorescence than Enamel. ${ }^{24}$

In the present study, the difference in fluorescence of $0.5 \mathrm{~mm}$ thickness of Aelite Enamel and Body was not significant, but this difference was significant for $1 \mathrm{~mm}$ thickness. In Aelite Body, increasing the thickness from 0.5 to $1 \mathrm{~mm}$ significantly decreased the fluorescence. This phenomenon is referred to as quenching. Fluorescence of 
a fluorescent material reaches its optimal level at a certain concentration. Fluorescence is due to the interaction of light and fluorescent particles, which are also present in depth. The fluorosed light is absorbed by the superficial particles. In other words, after exceeding the optimal threshold, the fluorosed light is absorbed by other particles and decreases the efficiency of fluorescence (quenching effect). The quenching phenomenon occurs when the thickness increases. ${ }^{25}$ In dental composites tested in our study, the density of fluorescent particles in $1 \mathrm{~mm}$ thickness was too low to show the quenching effect. Thus, although thickness affects the fluorescence, this effect has an ascending trend to some extent and then descends due to the quenching effect. ${ }^{25}$

Opacity is caused by light scattering in the media. If light does not reach the fluorescent particles, fluorescence does not occur. The quenching phenomenon was more commonly seen in Body compared to Enamel type of composite resins in our study. The reduction in fluorescence as the result of increasing the thickness of Aelite composite was greater in Body compared to Enamel type of this composite. Clinically, the masking effect of Body composite type is higher than that of Enamel type. Under constant conditions in terms of thickness and density of fluorescent particles, the opaquer a material, the lower the fluorescence would be, because the odds of light reaching the fluorescent particles would decrease. This statement was confirmed by our findings. Our results showed that the fluorescence of $0.5 \mathrm{~mm}$ thickness of Enamel composite type was higher than that of Body type. From the clinical point of view, Z350 is more translucent than Aelite composite. Thus, light can better pass through it and scatter in the media and proceed. Therefore, the difference observed between different thicknesses of Z350 was not as large as that observed for Aelite. Small difference in masking ability of Z350 Body and Enamel (compared to Aelite) can explain no change in fluorescence following changing the thickness of $Z 350$ composite.

In our study, the opalescence of $1 \mathrm{~mm}$ thickness of Aelite Body and Enamel was higher than that of $0.5 \mathrm{~mm}$ thickness. This difference was not significant for Z350. This result was in line with the findings of previous studies. Arimotoa et $\mathrm{al}^{13}$ evaluated three types of composites and noticed that by an increase in thickness, the opalescence increased. They added that in thicknesses over $1 \mathrm{~mm}$, opalescence is affected by translucency and translucency significantly decreases following significant increase in opalescence. ${ }^{13}$

The opalescence of Aelite composite was higher than that of Z350 in all groups in our study. Lee et $\mathrm{al}^{5}$ compared the opalescence of four types of translucent composites and an unfilled resin. The opalescence of composites was found to be higher, which was in line with our findings. They also concluded that the opalescence of composites may vary depending on the brand and shade of composite resins. Yu and Lee ${ }^{26}$ compared the opalescence of direct and indirect composites and ceramics and found that opalescence changes under irradiated light, and in daylight it is less than that in presence of conventional and fluorescent lamps. Lee ${ }^{16}$ showed that addition of nano-TiO2 in 0.25 to $0.1 \%$ concentration in $1 \mathrm{~mm}$ thickness of composite increased its opalescence and similarity to tooth structure.
Our study showed that the interaction effect of type and brand of composite on opalescence was not significant. In Aelite, increasing the thickness increased the opalescence. Increasing the thickness increases the number of light scattering particles in the path of light. Thus, opalescence increases, unless the sample is so translucent that the effect of thickness is neutralized..$^{27}$ For instance, $Z 350$ is more translucent than Aelite. Thus, the increase in opalescence that occurs by an increase in thickness of Aelite was not seen in Z350. Clinical evidence shows that Aelite has greater opacity than Z350. By an increase in thickness, the density of light scattering particles increases as well. Thus, greater opalescence is expected by an increase in thickness. Another important factor in this regard is the density of the light scattering particles in the media. The manufacturers of composite resins can increase the density to reach optimal results at a lower thickness. ${ }^{27}$ Some certain relationships exist between the particle dimensions and light scattering, referred to as the Rayleigh scattering of light. When light hits small particles with a reflectance different from that of their surrounding environment, it is scattered. The amount of scattered light highly depends on the difference between the refractive index of particles and their surrounding environment. When the particles and their surrounding environment have similar refractive index, light is not scattered at all and the border between the two is not seen. Light scattering also depends on the size of particles. Small particles scatter small amount of light. Increasing the size of particles increases light scattering until it reaches the light wavelength and then decreases for larger particles. ${ }^{27}$ Therefore, when pigments have a different refractive index from that of resin, and when their diameter is almost equal to the wavelength of light, they are as efficient as those scattering light. When pigments are too small and have a refractive index similar to that of resin, they scatter a small amount of light and appear translucent. Thus, light scattering can be adjusted by selecting pigments of desired size with a certain refractive index. However, by coating small pigments with iron oxide, translucency can be achieved by minimizing the difference in the refractive index of pigments and resin. Light can be scattered by controlling the size of organic pigments instead of paying attention to the difference in refractive indexes. Considering the size of pigments, small changes can affect light scattering and color. Knowledge about the scattering and absorption properties of pigments and their functional wavelength enables more accurate estimation of the final color. ${ }^{27}$ The composite manufacturers can work on the size of particles to achieve the desired opalescence.

In our study, the opalescence of Aelite was higher than that of Z350 because Z350 is more translucent and has a smaller share of light scattering particles. Significant difference between Z350 and Aelite can be due to the nano-behavior of Z350 and presence of tiny translucent particles in its composition. The opalescence value of Enamel and dentin has been reported to be 22.9. ${ }^{12}$ Thus, the current findings suggest that the opalescence of Aelite is closer to that of Enamel and dentin. The difference in opalescence of the two composites tested in our study seems to be attributed to the difference in their composition and size of fillers. ${ }^{12}$ 
Future studies with larger sample size are required to assess the fluorescence and opalescence of other brands of composite resins. Also, the relationship of opacity and fluorescence should be quantified in the future studies. Last but not least, color change can be used as the fluorescence factor and the results can be interpreted by taking into account the color change parameter.

\section{Conclusion}

Within the limitations of this study, the results showed that thickness, type, and brand of composite resins affect their fluorescence and opalescence.

\section{Conflict of Interest}

None declared.

\section{Acknowledgment}

The authors thank Dr. Kharazifard for statistical analysis.

\section{References}

1 Anusavice K, Phillips' Science of Dental Materials. 11th edition. St Louis, MO: Saunders; 2003:6-47

2 Primus CM, Chu CC, Shelby JE, Buldrini E, Heckle CE. Opalescence of dental porcelain enamels. Quintessence Int 2002;33(6):439-449

3 Nohl FS, Steele JG, Wassell RW. Crowns and other extra-coronal restorations: aesthetic control. Br Dent J 2002;192(8):443$450,445-450$

4 Kobashigawa A, Angeletakis C, Opalescence Fillers for Dental Restorative Composite. Alexandria, Virginia: United States Patent and Trademark Office US Patent; 2001;6(232):367

5 Lee YK, Lu H, Powers JM. Measurement of opalescence of resin composites. Dent Mater 2005;21(11):1068-1074

6 Lee YK, Yu B. Measurement of opalescence of tooth enamel. J Dent 2007;35(8):690-694

7 Hafström-Björkman U, Sundström F, ten Bosch JJ. Fluorescence in dissolved fractions of human enamel. Acta Odontol Scand 1991;49(3):133-138

8 Spitzer D, Bosch JJ. The total luminescence of bovine and human dental enamel. Calcif Tissue Res 1976;20(2):201-208

9 McLaren EA. Luminescent veneers. J Esthet Dent 1997;9(1):3-12

10 Lee YK, Lu H, Powers JM. Fluorescence of layered resin composites. J Esthet Restor Dent 2005;17(2):93-100, discussion 101

11 Lee YK, Lu H, Powers JM. Changes in opalescence and fluorescence properties of resin composites after accelerated aging. Dent Mater 2006;22(7):653-660
12 Lee YK. Opalescence of human teeth and dental esthetic restorative materials. Dent Mater J 2016;35(6):845-854

13 Arimoto A, Nakajima M, Hosaka K, et al.Translucency, opalescence and light transmission characteristics of light-cured resin composites. Dent Mater 2010;26(11):1090-1097

14 Lee YK, Powers JM. Influence of opalescence and fluorescence properties on the light transmittance of resin composite as a function of wavelength. Am J Dent 2006;19(5):283-288

15 Lim YK, Lee YK, Lim BS, Rhee SH, Yang HC. Influence of filler distribution on the color parameters of experimental resin composites. Dent Mater 2008;24(1):67-73

16 Lee YK. Influence of filler on the difference between the transmitted and reflected colors of experimental resin composites. Dent Mater 2008;24(9):1243-1247

17 Azzopardi N, Moharamzadeh K, Wood DJ. Martin N, van Noort R. Effect of resin matrix composition on the translucency of experimental dental composite resins. Dent Mater 2009;25(12):1564-1568

18 Arikawa H, Kanie T, Fujii K, Takahashi H, Ban S. Effect of filler properties in composite resins on light transmittance characteristics and color. Dent Mater J 2007;26(1):38-44

19 Hashemikamangar SS, Pourhashemi SJ, Talebi M, Kiomarsi N, Kharazifard MJ. Effect of organic acids in dental biofilm on microhardness of a silorane-based composite. Restor Dent Endod 2015;40(3):188-194

20 Yeh ST, Wang HT, Liao HY, et al.The roughness, microhardness, and surface analysis of nanocomposites after application of topical fluoride gels. Dent Mater 2011;27(2):187-196

21 Tuncer S, Demirci M, Tiryaki M, Unlü N, Uysal Ö. The effect of a modeling resin and thermocycling on the surface hardness, roughness, and color of different resin composites. J Esthet Restor Dent 2013;25(6):404-419

22 Renne WG. Commentary: effect of bleaching on staining susceptibility of resin composite restorative materials. J Esthet Restor Dent 2009;21(6):415

23 Korkmaz Y, Ozel E, Attar N, Aksoy G. The influence of one-step polishing systems on the surface roughness and microhardness of nanocomposites. Oper Dent 2008;33(1):44-50

24 Meller C, Klein C. Fluorescence of composite resins: a comparison among properties of commercial shades. Dent Mater J 2015;34(6):754-765

25 McDonald R. Colour Physics for Industry. 2nd edition. England: Staples Printers Rochester Ltd; 1997

26 Yu B, Lee YK. Difference in opalescence of restorative materials by the illuminant. Dent Mater 2009;25(8):1014-1021

27 Berns Roy S, Saltzmans Billmeyer. Principles of Colour Technology 3rd edition. London John Wiley and Sons Inc.; January $1 ; 1967$ 